\title{
Classification and treatment of different stages of alzheimer's disease using various machine learning methods
}

\author{
Sandhya Joshi ${ }^{1}$, Vibhudendra Simha G.G. ${ }^{2}$, Deepa Shenoy P. ${ }^{2}$, Venugopal K.R. ${ }^{2}$, Patnaik L.M. ${ }^{3}$ \\ ${ }^{1}$ Research Scholar, Department of Computer Science and Engineering, M G R University, Chennai, India, \\ sanjoshi17@yahoo.com \\ ${ }^{2}$ Department of Computer Science and Engineering, University Visvesvaraya College of Engineering, K R \\ Circle, Bangalore-01, India \\ ${ }^{3}$ Vice Chancellor, Defence Institute of Advanced Technology, Pune, India
}

\begin{abstract}
There has been a steady rise in the number of patients suffering from Alzheimer's disease (AD) all over the world. Medical diagnosis is an important but complicated task that should be performed accurately and efficiently and its automation would be very useful. The patient's records are collected from National Institute on Aging, USA. The Sample consisted of initial visits of 496 subjects seen either as control or as patients. Patients were concerned about their memory at the National Institute on Aging. It also consisted of patients and caregiver interviews. This research work presents different models for the classification of different stages of Alzheimer's disease using various machine learning methods such as Neural Networks, Multilayer Perceptron, Bagging, Decision tree, CANFIS and Genetic algorithms. The classification accuracy for CANFIS was found to be $99.55 \%$ which was found to be better when compared to other classification methods. Based on the outcome of classification accuracies, various management and treatment strategies such as pharmacotherapeutic and non pharmacotherapeutic interventions for mild, moderate and severe AD were elucidated, which can be of enormous use for the medical professionals in diagnosis and treatment of $A D$.
\end{abstract}

Keywords: Alzheimer's Disease, Neural Networks, Multilayer Perceptron, Bagging, Decision tree, CANFIS and Genetic Algorithms, Pharmacotherapeutic intervention, Non-Pharmacotherapeutic intervention

\section{Introduction}

Alzheimer's disease is a progressive neurodegenerative brain disorder that is slow in onset but leads to dementia, unusual behavior, personality changes and ultimately death [1]. The personality distortions interfere with the patient's professional life, social activities and relationships [2]. It is a chronic, progressive disabling organic brain disorder characterized by disturbance of multiple cortical functions, including memory, judgment, orientation, comprehension, learning capacity and language [3]. The most common cause of dementia in the elderly is probably Alzheimer's disease (AD) [4]. The National Institute of Health predicts, if the current trend continues, there will be more than 8.5 million $A D$ patients by the year 2030 in the USA alone [5]. Alzheimer's disease (AD) was first described by the German psychiatrist, Alois Alzheimer, in 1907. The disease appeared less common in the early decades of the 20th century. Although there are a number of medical areas to which Machine Learning (ML) systems have been applied, dementia has not been one of them. Yet $A D$ is a complex problem with correct diagnosis requiring historical data, physical exam, cognitive testing, laboratory investigations etc. Although diagnostic accuracy using clinical NINCDS-ADRDA criteria for probable $A D$ is about $88 \%$ compared to post-mortem diagnosis [6] most demented patients with AD are seen by community physicians who often do not detect $A D$ or misdiagnose it [7]. This problem is compounded by the average delay of 4 years between symptom onset and first physician contact [8] which usually related to the patient's social embarrassment about having a memory problem. At this point of the disease, physicians are less able to slow the progression and minimize debilitating behavioral effects of the AD. A simple unobtrusive method for detecting $A D$ early in the disease's course would help get patients to seek early evaluation and treatment. Early detection and correct diagnosis can lead to disease-retarding therapies which can slow disease progression and reduce patient and caregiver stress and morbidities. At present there are many more classification algorithms for example classification based on decision tree, Bayesian classification etc. But we need to apply such a algorithm to deal with all kinds of neuropsychological tests, mental status examinations and laboratory investigations, by which we will get best possible treatments for $A D$ according to the investigation reports entered in the database and thus we can manage AD very well. The article puts forward the usage of existing Machine learning methods for the classification of different stages of $A D$ as mild, moderate, severe and Normal. The next part of this paper presents the best possible treatment and the management for the various stages of Alzheimer's disease.

\section{Literature Survey}

A detailed study on classification of $A D$ and diagnosis of $A D$ has been proposed by many researchers. This section includes a brief survey of the related work. A method of estimating the 
progression rates in Alzheimer's disease and diagnosis of dementia is presented in [9].The combination of cognitive testing and an informant questionnaire in screening for dementia is proposed in [10]. Variability in Mini-Mental State Examination score in patients with probable Alzheimer's disease is presented in [11]. David F. Tang-Wai and David S. Knopman [12] proposed the Comparison of the Short Test of Mental Status and the Mini-Mental State Examination in Mild Cognitive Impairment. Detecting very early stages of dementia from normal aging with machine learning methods proposed by Shankle, WR., Mani, S., Pazzani, M. [13].

A study on the prediction of various diseases using artificial neural networks and genetic algorithms has been proposed by many researchers. Yasuyuki Tomita et al. [14] proposed Artificial Neural Network Model for Prediction of Childhood Allergic Asthma Using Single Nucleotide Polymorphism Data. In order to predict development of disease, they applied a knowledge processing method based on an artificial neural network (ANN) model to diagnostic prediction of 172 subjects with childhood allergic asthma (CAA) and 172 healthy subjects. Prediction of Radiation Induced Liver Disease (RILD) using Artificial Neural Networks was proposed by Ji Zhu et al. [15]. A total of 93 primary liver carcinoma (PLC) patients with single lesion and associated with hepatic cirrhosis of Child-Pugh grade A were treated with hypofractionated three-dimensional conformal radiotherapy (3DCRT). Eight out of 93 patients were diagnosed RILD. The Prediction of major histocompatibility complex Class II-Peptide Interaction Using Fuzzy Neural Network is proposed by Hideki Noguchi and Taizo Hanai in [16].

\section{Motivation}

Until recently, the most significant issue facing a family physician is the diagnosis and treatment of AD. However, as more treatment options become available, it will become increasingly important to diagnose AD early. Dementia of AD type may be suspected if memory deficits are exhibited during the medical history and physical examination. Information from the patient's family members, friends and caregivers may also point to signs of AD. Distinguishing age-related cognitive decline, mild cognitive impairment and Alzheimer's disease may be difficult and requires evaluation of cognitive and functional status. The prevalence of $A D$ is expected to increase dramatically in future years as life expectancy continues to increase and the baby-boomer population ages. The cumulative incidence of Alzheimer's disease has been estimated to be as high as 4.7 percent by age $70,18.2$ percent by age 80 and 49.6 percent by age 90 . Proposed risk factors for $A D$ include a family history of dementia, previous head injury, lower educational level and female sex. Alzheimer's disease is the most common cause of dementia; many of the remaining cases of dementia are caused by vascular disease and Lewy body disease. Vascular disease and Lewy body disease often occur in combination with Alzheimer's disease. Hence there is an urgent need to understand the disease, to develop prophylactic strategies which can distinguish the different states of $A D$, so that the proper step can be taken to manage the disease.

\section{Problem Definition}

The sample consists of initial visits of 496 subjects seen either as control or as patients. Patients were concerned about their memory at the National Institute on Aging consists of patients and caregiver interviews. The Neurologists and Neurophysiologists apply the DSM-IV [17] criteria along with some laboratory investigations to classify the subject's mental status as either normal, cognitively impaired i.e. dementia of Alzheimer's type. The dataset consists of 35 attributes broadly classified under five main observations namely age, neuropsychiatry assessments, mental status examination and laboratory investigations. Entire description of patient's data set is shown in the table 1. The first focus of our work is on classification of various stages of Alzheimer's disease, the next stage proposes the various possible treatments and the management for each stage of $A D$.

Table 1. Description of Patient's Dataset

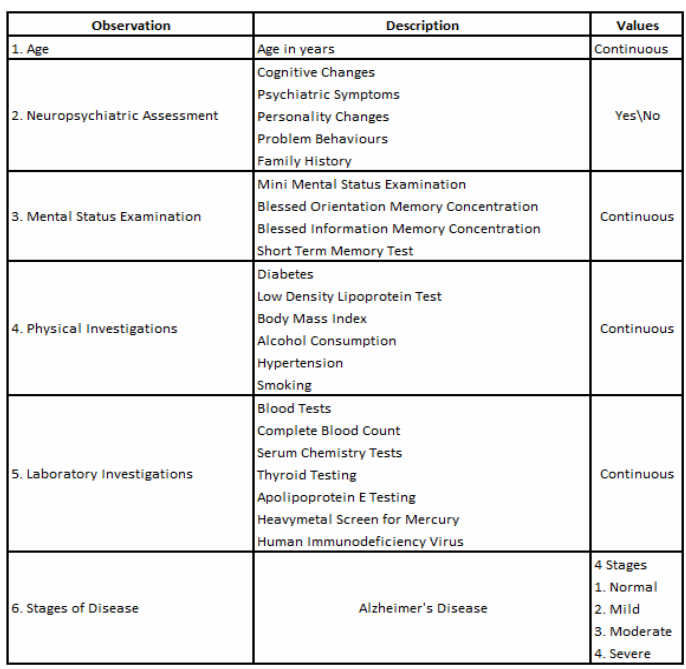

Model

The Architecture and modelling of the current paper is depicted in Fig 1. It begins with the collection of patients records, which is followed by preprocessing of data set includes converting the data in to numeric values. Next stage is evaluating the attributes by using gain ratio attribute evaluation scheme with ranker search 
method. The main focus of our work is on classification of various stages of $A D$ using various Machine learning methods. The last and the most important stage is treatment and management of $A D$, in this stage we suggest different approaches for the management for each of the classified stages of AD.

\begin{tabular}{|c|c|c|c|c|c|}
\hline $\begin{array}{l}\text { Collection of } \\
\text { Patient's Becordos }\end{array}$ & $\begin{array}{l}\text { Pee- Processing of } \\
\text { Patert's Records }\end{array}$ & $\begin{array}{l}\text { Selection of } \\
\text { Attributes }\end{array}$ & Classitication & Treatrime & Mamagement \\
\hline
\end{tabular}

Fig. 1- Architecture of Classification of Different Stages of Alzheimer's disease

\section{Collection of Patient's Records}

The patient's records are collected from National Institute on Aging, USA. The data set in our study consists of initial visits of 496 subjects seen either as control or as patients. Patients were concerned about their memory at the NIA, consists of patients and caregiver interviews. The neurologists and Neurophysiologists apply the DSM-IV criteria along with some laboratory investigations to classify the subject's mental status as either normal, cognitively impaired i. e. dementia of Alzheimer's type. The National Institute on Aging, a component of the National Institutes of Health, USA supports 28 Alzheimer's disease Centers across the country.

\section{Pre-Processing Patient's Records}

In our study most of the collected data is free from outliers, noise and missing data. Some inconsistencies are recorded in the data set these consistencies are corrected manually by using external references.

\section{Attribute Selection}

Attribute selection involves searching through all possible combinations of attributes in the data to find which subset of attributes works best for prediction and classification. For classification tasks, it can lead to increased accuracy or to reduced computational costs. In the present study we used Gain ratio ranker search method for selecting the attributes.

Gain ratio is defined by the formula:

Gain ratio = Information Gain / Split Information (1)

Where, Info Gain (Class, Attribute) $=\mathrm{H}$ (Class) $\mathrm{H}$ (Class/Attribute),

Where $\mathrm{H}$ is the information entropy.

\section{Classification of Diseases}

Classification is the most commonly used data mining technique, which involves the separation of data into segments which are non-overlapping. Classification can be viewed as forecasting a discrete value. Any approach to classification assumes some knowledge about the data. Hence a training set is used to identify specific parameters. Training data requires sample input data, domain expertise, and a classification assignment to the data. In the present study we used five different Machine Learning methods such as Decision tree [18], Bagging [19], Neural Networks, Multilayer Perceptron [20], CANFIS and Genetic Algorithms for the classification of various stages of Alzheimer's disease.

\begin{abstract}
Machine Learning (ML)
Machine Learning and Knowledge Discovery from Databases (KDD) are increasingly being applied in health care to build models, develop practice guidelines or refine guidelines for better medical decision making. They differ from traditional approaches by generating domain models such as decision trees, decision rules, graphs etc. from data. ML methods attempt to learn a description that best separates the different stages of Alzheimer's disease. As input, each of the initial visits is represented with the attributes described above. The output of each of the learning methods is a representation of the different stages of Alzheimer's disease that can be applied to classify patients with an unknown Alzheimer's stage. Each learning method applies a different search technique and concept representation to describe the possible outcomes of the diagnosis. In the proposed system we have applied each of the five ML methods for the classification of different stages of Alzheimer's disease.
\end{abstract}

\section{Neural Networks (NN)}

Neural networks are very sophisticated modelling techniques capable of modelling extremely complex functions. The Neural network is developed based on the human nervous system and the neuron is the fundamental element. A neuron has several inputs and only one output. The neural network consists of three layers 1.Input layer 2. Hidden layer 3.Output layer. The layers are connected with weighted edges. These edges are trained and initialized.

\section{Multilayer Perceptrons (MLPs)}

Multilayer Perceptrons are feed forward neural networks trained with the standard back propagation algorithm. They are supervised networks so they require a desired response to be trained. They learn how to transform input data into a desired response, so they are widely used for pattern classification. With one or two hidden layers, they can approximate virtually any input-output map. They have been shown to approximate the performance of optimal statistical classifiers in difficult problems. Most neural network applications involve MLPs. This is perhaps the most popular network architecture in use today.

In a Multilayer Perceptron topology neurons are grouped into distinct layers. Output of each layer is connected to input of nodes in the following 
layer. Inputs of the first layer (input layer) are the inputs to the network while the outputs of the last layer, form the output of the network. A multilayer perceptron is especially useful for approximating a classification function that maps input vector $(\mathrm{x} 1, \mathrm{x} 2, \ldots \mathrm{xn})$ to one or more classes $\mathrm{C} 1, \mathrm{C} 2, \ldots \mathrm{Cm}$. By optimizing weights and thresholds for all nodes, the network can represent a wide range of classification functions. Optimizing the weights can be done by supervised learning, where the network learns from the large number of examples. Examples are usually provided one at a time. For each example the actual vector is computed and compared to the desired output.

Then, weights and thresholds are adjusted, proportional to their contribution to the error made at the respective output. One of the most used methods is the back-propagation method, in which in the iterative manner, the errors are propagated (error $=$ the difference between desired output and the output of actual ANN) into the lower layers, to be used for the adaptation of weights.

\section{CANFIS and Genetic Algorithms}

The CANFIS model integrates adaptable fuzzy inputs with a modular neural network to rapidly and accurately approximate complex functions. Solves problems more efficiently than neural networks when the underlying function to model is highly variable or locally extreme.

The fundamental component of CANFIS is a fuzzy axon, which applies membership functions to the inputs. The output of a fuzzy axon is computed using the following formula:

fj $(x, w)=\operatorname{mini}(M F(x i, w i j)),(2)$

Where $\mathrm{i}=$ input index, $\mathrm{j}=$ output index, $\mathrm{xi}=$ input $\mathrm{i}$, wij=weights (MF parameters) corresponding to the jth MF of input $i$ and $M F=$ membership function of the particular subclass of the fuzzy axon. This system can be viewed as a special three-layer feed forward neural network. The first layer represents input variables, the middle (hidden) layer represents fuzzy rules and the third layer represents output variables. In order to improve the learning of the CANFIS, quicker training and enhance its performance, we use genetic algorithms to search for the best number of MF for each input, and optimization of control parameters such as learning rate, and momentum coefficient. This approach also is useful to select the most relevant features of the training data which can produce a smaller and less complicated network, with the ability to generalize on freshly presented data, due to the removal of redundant variables. GAs causes the initial population to evolve towards a population that is expected to contain the best solution.

Bootstrap aggregating (bagging)

Bagging is a machine learning ensemble metaalgorithm to improve machine learning of classification and regression models in terms of stability and classification accuracy. Although it is usually applied to decision tree models, it can be used with any type of model. Bagging is a special case of the model averaging approach. In bagging for each trail $t=1,2,3, \ldots T$, a training set of size $\mathrm{N}$ is sampled from the original instances. This training set is the same size as the original data, but some instances may not appear more than once. The learning system generates a classifier $\mathrm{Ct}$ from the sample and the final classifier $\mathrm{C}^{*}$ is formed by aggregating the $\mathrm{T}$ classifiers from these trails. To classify an instance $\mathrm{x}$, a vote for the class $\mathrm{k}$ is recorded by every classifier for which $\mathrm{Ct}(\mathrm{x})=\mathrm{k}$ and $\mathrm{C}^{*}(\mathrm{x})$ is then the class with the most votes.

\section{Implementation and Performance Analysis}

The data set in our study consists of 496 training cases and 225 testing cases, with 35 attributes broadly classified under five main observations namely age, neuropsychiatry assessments, mental status examination, laboratory investigations and physical examinations. The description of the data classification is shown in table 2. The proposed model begins with selection of attributes using gain ratio attribute selection method on the given data set. On the outcome of the selection method different models were simulated using various $\mathrm{ML}$ methods such as decision tree, Bagging method, Neural Network method, Multilayer Perceptron, CANFIS and Genetic Algorithms for the classification of different stages of Alzheimer's disease. For the simulation purpose we have used software's namely WEKA (Waikato Environment for Knowledge Analysis) for decision tree and bagging methods. Matlab software was used for developing Neural Network and Multilayer Perceptron model in addition to these the simulations were realized by using NeuroSolution software for CANFIS and Genetic Algorithm. Results of classification accuracies using various $\mathrm{ML}$ methods are shown in table 3. The classification accuracy for CANFIS was found to be $99.55 \%$ which was found to be better when compared to other classification methods. Classification accuracy is almost same for C4.5 and multilayer Perceptron, but the runtime for C4.5 is comparatively higher. The classification matrix of $\mathrm{C} 4.5$ obtained for 225 testing sample set is shown in table 4 . The classification matrix provides a comprehensive picture of the classification performance of the classifier. The ideal classification matrix is the one in which the sum of the diagonal is equal to the number of samples. Figure 2 shows the Output Vs Desired Plot for the test set using CANFIS and genetic algorithm. Once the classification is done the next stage would be finding the best possible treatment and management for Alzheimer's diseases. 
Table 2- Description of Data Classification

\begin{tabular}{|c|c|c|c|c|}
\hline 0 & Noumal & Milid & Moderate & Semer \\
\hline Traime datuet & 98 & 140 & 138 & 121 \\
\hline Testing dataset & 0 & 6 & I & 45 \\
\hline
\end{tabular}

Table 3- Results of classification accuracies using various Machine learning methods

\begin{tabular}{|c|c|c|c|c|}
\hline $\begin{array}{l}\text { ML methods } \\
\text { C45 }\end{array}$ & $\begin{array}{l}\text { Chaifiotion } \\
\text { anway } \\
909\end{array}$ & $\begin{array}{c}\text { Rurtme } \\
\text { (mec) } \\
0.03 \\
0.03\end{array}$ & $\begin{array}{l}\text { Sensitity } \\
6 \% \\
961\end{array}$ & $\begin{array}{l}\text { Spoificity } \\
(69) \\
9794\end{array}$ \\
\hline Batize & 9.4 & 0.05 & 9792 & 96 \\
\hline Newal Netrows & 922 & 0.018 & 962 & 988 \\
\hline Mnlitian Fereptron & 999 & 0.015 & 901 & 9894 \\
\hline CAMFIS and Gereto Hlonitum & 95 & $0.0 \%$ & 92 & 99 \\
\hline
\end{tabular}

Table 4- Classification matrix for test set (225 test samples)

\begin{tabular}{|c|c|c|c|l|}
\hline Class & Nortmal & Mild & Moderate & Severe \\
\hline True & 62 & 67 & 50 & 45 \\
\hline False & 0 & 0 & 1 & 0 \\
\hline
\end{tabular}

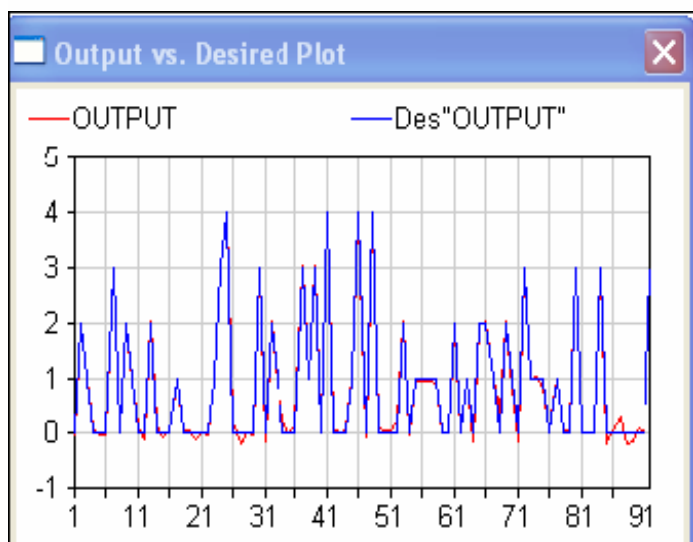

Fig. 2- Output Vs Desired Plot for the Alzheimer's Database

\footnotetext{
Pharmacotherapeutic and NonPharmacotherapeutic Management of AD

Regular medical management of general health, in addition to monitoring of cognitive deficits, is essential. Management objectives and interventions should be based on psychiatric, neurological and general medical evaluations of the nature and cause of cognitive deficits and associated non-cognitive symptoms. Cholinesterase Inhibitors: These agents are approved for monotherapy as well as combination therapy to improve cognitive functions or delay decline in patients with mild to moderate and severe AD. NMDA (N-methyl-Daspartate) antagonist: various randomized, placebo - controlled, double blind studies have revealed the efficacy of memantine, the only available NMDA antagonist as a treatment for $A D$. These have indicated its effects on cognition,
}

activities of daily living and behavior. Antioxidant therapy with Vitamin E etc was found to postpone functional decline. Various natural antioxidant derived from plants were also found be beneficial. Hormonal replacement therapy (HRT) using estrogen was found to delay the onset of AD. (Refer Table 6). AD was found to be associated with various associated behavioral disturbances (mood disorder, apathy, anxiety) which can be treated by using pharmacotherapeutic agents (Table 5). AD patients suffer from behavioral outbreaks such as mood disorder, sleep disorder, irritation, etc which can be managed by adopting simple helpful non-pharmacological strategies (Table 7).

\section{Conclusion}

This paper proposes a various models for the classification of different stages of Alzheimer's disease by considering the different cognitive tests, physical examinations, age, neuropsychiatry assessments, mental status examination and laboratory investigations. The classification accuracy for CANFIS was found to be $99.55 \%$ which was better when compared to other classification methods. The classification model was validated with the test cases and the model achieved an average classification accuracy of $99.25 \%$. Based on the outcome of classification accuracies, various management and treatment strategies such as pharmacotherapeutic and non pharmacotherapeutic interventions for mild, moderate and severe AD were elucidated, which can be of enormous use for medical professionals in diagnosis and treatment of $A D$. It was observed that Donepezil hydrochloride, Galantamine, Rivastigmine tartrate, Rivastigmine, Memantine are the most prescribed drugs for the treatment of Mild, Moderate and Severe Alzheimer's Disease.

\section{Acknowledgments}

We would like to thank Dallas Anderson, National Institute of Aging, USA, and Nancy Lombardo, National Institute of Health, USA, for providing the data sets. Authors would like to thank Dr. Richard J. Hodes Director of National Institute on Aging (NIA), the component of the National Institutes of Health, USA for providing useful information.

\section{References}

[1] Jewart R.D., Green J., Lu C.J., Cellar J., Tune L.E. (2005) Am J Geriatr Psychiatry. 13, 324-328.

[2] Braak H. and Braak E. (1991) Acta Neuropathol (Berl). Vol-82, pg 239-259

[3] Robert Katzman, Claudia Kawas, (1998) Neuro Science News. 1, 27-44.

[4] Cummings J.L., Cole G. (2002) JAMA., 287 (18), 2335-2348. 
[5] Doody R.S., Stevens J.C., Beck R.N., Dubinsky R.M., Koye, J.A., Gwyther L. (2001) Neurology, 56, 1154-1166.

[6] Kazee A.M. Eskin T.A., Lapham L.W., Gabriel K.R. and Hamill R.W. (1993) Alzheimer's disease and Associated disorders. 7, 152-164.

[7] Hoffman R.S. (1982) JAMA. 248, 225-228.

[8] Cononor D.W., Fertig A., Grande M.J., Hyde J.B. and Wraight S.K. (1993) $\mathrm{Br} J$ Gen Pract., 43, 185-188.

[9] Rachelle Smith Doody, Paul Massman and Kay Dunn J. (2005) Arch Neurol., 58, 55-58.

[10] Richard Knafelc, Dina Lo Giudice, Susan Harrigan, Roslyn Cook, Leon Flicker, Andrew Mackinnon, David Ames (2003) Age and Ageing. 32, 541-547.

[11] Christopher, Clark, M., Lianne Sheppard D. and Gerda G., Heyman (2008) Arch Neurol., 56, 4-8.

[12] David F., Tang-Wai, David S., Knopman E., Yonas G., Tangalos F., Bradley Boeve, Ronald C. and Petersen (2003) Arch Neurol. 60, 1777-1781.

[13] Shankle W.R., Mani S., Pazzani M. and Smyth (1997) Artificial Intelligence in Medicine, AIME., 1211, 73-85.

[14] Yasuyuki Tomita, Shuta Tomida, Yoichi Suzuki, (2003) Genome Informatics, 14, 593-594.

[15] Zhu Ji. (2007) Jpn, J, Clin, Oncol., 36, 783788.

[16] Hideki Noguchi, Taizo Hanai, Hiroyuki Honda, Takeshi Kobayashi, (2002) Journal of Healthcare Information Management. 16, 50-559.

[17] American Psychiatric Association. Diagnostic and statistical manual of mental disorders, 4th edition. Washington, D.C.

[18] Honig L.S., Tang M.X., Albert S., et al, (2003) Arch Neurol., 60, 1707-1712.

[19] Vermeer S.E., Prins N.D., den Heijer T., Hofman A., Koudstaal P.J., Breteler M.M. (2003) N Engl J Med., 348, 12151222.

[20] Breiman L. (2001) Machine Learning., 45, 5-32. 
Sandhya Joshi, Vibhudendra Simha GG, Deepa Shenoy P, Venugopal KR, Patnaik LM

Table 5- Pharmacotherapy of Alzheimer's Disease (Stage: Mild and Moderate)

\begin{tabular}{|c|c|c|}
\hline $\begin{array}{l}\text { Pharmacological Treatment of } \\
\text { Behavior and Mood } \\
\text { (Prescribed Drugs) }\end{array}$ & Dosage & Comments and cautions \\
\hline ANTIPSYCHOTICS & \multicolumn{2}{|c|}{$\begin{array}{l}\text { Used to control problematic delusions, hallucinations, severe psychomotor } \\
\text { agitation, and combativeness. }\end{array}$} \\
\hline Aripripazole (Abilify $(\mathbb{B})$ & $\begin{array}{l}\text { Initial dose: } 5 \mathrm{mg} / \text { day } \\
\text { (Mintzer et al., 2007) }\end{array}$ & $\begin{array}{l}\text { Generally classified as non-sedating, weight neutral } \\
\text { Dopamine blocker with agonist properties } \\
\text { Modest documentation }\end{array}$ \\
\hline Clozapine (Clozaril(B) & $\begin{array}{l}\text { Initial dose: } 12.5 \mathrm{mg} \text { twice daily- } \\
\text { Max: } 75-150 \mathrm{mg} \text { (in divided doses) }\end{array}$ & $\begin{array}{l}\text { Must monitor HgbAlc, blood sugar (for possible new } \\
\text { onset diabetes) and cholesterol every } 3 \text { months } \\
\text { Do not use with bactrim or tegretol (due to increased } \\
\text { risk of agranulocytosis), }\end{array}$ \\
\hline $\begin{array}{l}\text { Ziprasidone } \\
(\text { Geodon } \mathbb{B})\end{array}$ & $\begin{array}{l}\text { Initial dose: } 10 \mathrm{mg} / \text { day } \\
\text { Max: } 80 \mathrm{mg} / \text { day Injectable: } 20 \mathrm{mg} \text { IM } \\
\text { (Berkowitz, 2003; Kohen, Preval, Southard, } \\
\text { \& Francis, 2005) }\end{array}$ & $\begin{array}{l}\text { Should be given with food to increase bioavailability } \\
\text { Generally classified as non-sedating, weight neutral }\end{array}$ \\
\hline $\begin{array}{l}\text { MOOD STABILIZERS } \\
\text { (ANTI-AGITATION AGENTS) }\end{array}$ & \multicolumn{2}{|c|}{$\begin{array}{l}\text { Used to control problematic delusions, hallucinations, severe } \\
\text { psychomotor agitation, and combativeness. Useful alternatives to antipsychotics for severe agitated, } \\
\text { impulsive, repetitive, and combative behaviors. }\end{array}$} \\
\hline Valproate (Depakote $\mathbb{B})$ & $\begin{array}{l}\text { Initial dose: } 25 \mathrm{mg} \text { twice } \\
\text { daily;-Titrate to maximum of } 300 \mathrm{mg} \text { daily in } \\
\text { divided doses }\end{array}$ & $\begin{array}{l}\text { Monitor liver enzymes; platelets \& PT/PTT as } \\
\text { indicated } \\
\text { Note: added lab tests increase cost and discomfort for } \\
\text { the patientFor impaired impulse control, aggressive } \\
\text { behavior, etc., consider a SSRI. }\end{array}$ \\
\hline Carbamazepine (Tegretol( $\bar{B})$ & $\begin{array}{l}\text { Initial dose: } 125 \mathrm{mg} \text { daily } \\
\text { Generally Titrate to Max.of } 500 \mathrm{mg} \text { twice } \\
\text { daily although some may go higher }\end{array}$ & $\begin{array}{l}\text { Monitor CBC and liver enzymes regularly } \\
\text { Drug Interactions } \\
\text { Problematic side effects-One controlled study (Tariot } \\
\text { et al., 1998) }\end{array}$ \\
\hline ANXIOLYTICS -BENZODIAZEPINES & \multicolumn{2}{|c|}{ For management of insomnia, anxiety, and acute agitation. } \\
\hline Lorazepam (Ativan $(\bar{B})$ & $\begin{array}{l}1 \mathrm{mg} \text { of lorazepam }=5 \text { to } 10 \mathrm{mg} \text { of diazepam } \\
\text { oral, sublingual, parenteral }\end{array}$ & $\begin{array}{l}\text { High potency, intermediate acting } \\
\text { NOTE: Lorazepam is not short-acting and is not safer } \\
\text { than other BDZs. The elderly are more sensitive to } \\
\text { BDZs than younger patients }\end{array}$ \\
\hline Clonazepam (Klonopin $\mathbb{B})$ & $1 \mathrm{mg}$ clonazepam $=1 \mathrm{mg}$ lorazepam & $\begin{array}{l}\text { High potency, long acting, Can be useful in BDZ } \\
\text { withdrawal. No active etabolite }\end{array}$ \\
\hline $\begin{array}{l}\text { ANXIOLYTICS-NON- } \\
\text { BENZODLAZEPINES }\end{array}$ & \multicolumn{2}{|l|}{ Useful in mild-moderate agitation only } \\
\hline Buspirone (Buspar $(\mathcal{B})$ & $\begin{array}{l}\text { Initial dose: } 5 \mathrm{mg} \text { twice daily } \\
\text { Max: } 20 \mathrm{mg} \text { three times daily }\end{array}$ & $\begin{array}{l}\text { May be useful in mild-moderate agitation only } \\
\text { May take } 2-4 \text { weeks to become effective } \\
\text { Poorly documented efficacy }\end{array}$ \\
\hline Zolpidem tartrate (Ambien $(\mathbb{B})$ & $\begin{array}{l}\text { Non-BDZ sleep med. } \\
5 \text { mg orally at bedtime }\end{array}$ & $\begin{array}{l}\text { Reduced hepatic clearance in the elderly } \\
\text { Amnestic syndrome, sleep walking, hallucinations }\end{array}$ \\
\hline ANTIDEPRESSANTS-TRICYCLICS & \multicolumn{2}{|c|}{$\begin{array}{l}\text { Useful for patients with Mild to moderate } \\
\text { General Cautions: A full therapeutic trial requires at least } 4-8 \text { weeks. As a rule, doses are increased using } \\
\text { increments of the initial dose every } 5-7 \text { days until therapeutic benefits or significant side effects become apparent. } \\
\text { After } 9 \text { months, reassess need for medications by dose reductions. Discontinuing medication over } 10-14 \text { days } \\
\text { limits withdrawal symptoms. }\end{array}$} \\
\hline $\begin{array}{c}\text { Desipramine } \\
\text { Norpramin } \mathbb{B} / \text { Petrofrane } \mathbb{B}\end{array}$ & $\begin{array}{l}\text { Initial dose: } 10-25 \mathrm{mg} \text { daily } \\
\text { Max: } 150 \mathrm{mg} \text { daily }\end{array}$ & $\begin{array}{l}\text { Lower risk for hypotensive and anticholinergic side } \\
\text { effects (anticholinergic activity less than } \\
\text { paroxetine),May cause tachycardia }\end{array}$ \\
\hline $\begin{array}{c}\text { Doxepin } \\
(\text { Sinequan } \mathbb{B} / \text { Adapin }(\mathbb{B})\end{array}$ & $\begin{array}{l}\text { Initial dose: } 10-25 \mathrm{mg} \text { at bedtime Max: } 150 \\
\text { mg daily }\end{array}$ & $\begin{array}{l}\text { Significant hypotensive and anticholinergic effects are } \\
\text { limiting }\end{array}$ \\
\hline $\begin{array}{c}\text { Nortriptyline } \\
\text { (Aventyl } \mathbb{B} / \text { Pamelor }(\mathbb{B})\end{array}$ & $\begin{array}{l}\text { Initial dose: } 10 \mathrm{mg} \text { at bedtime ,Max: } 100 \mathrm{mg} \\
\text { daily }\end{array}$ & $\begin{array}{l}\text { Tolerance profile similar to desipramine but tends to } \\
\text { be more sedating,more anticholinergic Moderate } \\
\text { anticholinergic activity Moderate sedation may be }\end{array}$ \\
\hline $\begin{array}{l}\text { ANTIDEPRESSANTS-HETERO-AND } \\
\text { NONCYCLICS SELECTIVE } \\
\text { SEROTONERGIC REUPTAKE } \\
\text { INHIBITORS (SSRIs) } \\
\end{array}$ & \multicolumn{2}{|c|}{$\begin{array}{l}\text { General Cautions: These agents may prolong the half-life of other drugs by inhibiting various CYP } 450 \text { isoenzymes. } \\
\text { As a class, typical side effects can include sweating, tremors, nervousness, insomnia/somnolence, dizziness, and } \\
\text { various gastrointestinal and sexual disturbances. Withdrawal effects may occur if agents are abruptly discontinued }\end{array}$} \\
\hline Citalopram (Celexa $\mathbb{B})$ & Initial dose: $10 \mathrm{mg}$ daily Max: $40 \mathrm{mg}$ daily & $\begin{array}{l}\text { Well tolerated; nausea and sleep disturbances in some } \\
\text { Demonstrated efficacy for treatment of BPSDs. }\end{array}$ \\
\hline Escitalopram (Lexaproß) & Initial dose: $10 \mathrm{mg}$ daily Max: $20 \mathrm{mg} /$ day & Well tolerated; nausea and sleep disturbances in some \\
\hline Fluoxetine (Prozac $B)$ & $\begin{array}{l}\text { Initial dose: } 10 \mathrm{mg} \text { every other day Max } 20 \\
\text { mg daily }\end{array}$ & $\begin{array}{l}\text { Activating, Very long half life, Side effects may not } \\
\text { manifest for a few weeks }\end{array}$ \\
\hline Fluvoxamine (Luvox $(\mathbb{B})$ & $\begin{array}{l}\text { Initial dose: } 25 \mathrm{mg} \text { daily Max: } 100 \mathrm{mg} \text { twice } \\
\text { daily- } \\
\text { Reduce by half when using with Coumadin, } \\
\text { Xanax, or Halcion }\end{array}$ & \\
\hline
\end{tabular}


Table 6-Pharmacotherapy of Alzheimer's Disease (Stage: Mild, Moderate and Severe)

\begin{tabular}{|c|c|c|}
\hline \multicolumn{3}{|c|}{ Cholinesterase Inhibitors (for Treatment of Mild, Moderate and Severe Alzheimer's Disease } \\
\hline $\begin{array}{l}\text { Donepezil hydrochloride } \\
\text { (Aricept } 8 \text { ) }\end{array}$ & $\begin{array}{l}\text { Start: } 5 \mathrm{mg} \text { daily } \\
\text { Escalation: } 10 \mathrm{mg} \text { daily after } 4-6 \\
\text { weeks if tolerated }\end{array}$ & $\begin{array}{l}5 \text { mg dose is effective } \\
\text { Caution when using in people with cardiac } \\
\text { conduction conditions such as symptomatic } \\
\text { bradycardia, or with a history of falls or syncope } \\
\text { (may want to avoid or seek cardiac consult) } \\
\end{array}$ \\
\hline $\begin{array}{l}\text { Galantamine } \\
\text { (Razadyne \&,Razadyne ER()) }\end{array}$ & $\begin{array}{l}\text { Immediate Release: } \\
\text { Start: } 4 \mathrm{mg} \text { twice daily } \\
\text { Escalation: } 8 \mathrm{mg} \text { twice daily after } 4 \\
\text { weeks. May increase to } 16 \mathrm{mg} \text { twice } \\
\text { daily after an additional } 4 \text { weeks. } \\
\text { Max: } 24 \mathrm{mg} / \text { day } \\
\text { Extended release } \\
\text { Start: } 8 \mathrm{mg} \text { daily or } 4 \mathrm{mg} \text { twice daily. } \\
\text { Escalation: } 16 \mathrm{mg} \text { daily after } 4 \text { weeks } \\
\text { or } 8 \mathrm{mg} \text { twice daily after } 4 \text { weeks. May } \\
\text { increase to } 24 \mathrm{mg} \text { per day ( } 32 \mathrm{mg} \text { per da } \\
\text { not more effective in Alzheimer's Disea }\end{array}$ & $\begin{array}{l}\text { Starting dose is not therapeutic. Maximum dose } 16 \\
\text { mg per day if renal impairment Other cautions same } \\
\text { as donepezil }\end{array}$ \\
\hline $\begin{array}{l}\text { Rivastigmine tartrate } \\
\text { (Exelon(8) }\end{array}$ & $\begin{array}{l}\text { Start: } 1.5 \mathrm{mg} \text { twice daily } \\
\text { Escalation: } 3 \mathrm{mg} \text { twice daily after } \\
4 \text { weeks. May increase to } 4.5 \mathrm{mg} \\
\text { twice daily after an additional } 4 \\
\text { weeks. May increase to } 6 \mathrm{mg} \text { twice } \\
\text { daily after an additional } 4 \text { weeks }\end{array}$ & $\begin{array}{l}\text { Starting dose is not therapeutic Cautions same as for } \\
\text { donepezil and galantamine }\end{array}$ \\
\hline $\begin{array}{l}\text { Rivastigmine } \\
\text { (Exelon(8) }\end{array}$ & $\begin{array}{l}\text { Start: } 4.6 \mathrm{mg} / 24 \text { hour patch daily. } \\
\text { Escalation: } 9.5 \mathrm{mg} / 24 \text { hour patch daily } \\
\text { after } 1 \text { month } \\
\text { When switching from oral to the patch: } \\
\text { For a total daily dose of less than } 6 \mathrm{mg} \\
\text { oral rivastigmine switch to } 4.6 \mathrm{mg} / 24 \\
\text { hour patch (first check medication } \\
\text { adherence); } \\
\text { For a total daily dose between } 6-12 \mathrm{mg} \\
\text { of oral rivastigmine switch to } 9.5 \mathrm{mg} / 24 \\
\text { hour patch } \\
\text { Apply the first patch on the day } \\
\text { following the last oral dose }\end{array}$ & $\begin{array}{l}\text { Starting dose is not therapeutic. Caution same as for } \\
\text { donepezil and galantamine }\end{array}$ \\
\hline \multicolumn{3}{|l|}{ NMDA } \\
\hline Memantine (Namenda(8) & $\begin{array}{l}\text { Start: } 5 \mathrm{mg} \text { daily for } 1 \text { week } \\
\text { Escalation: } 5 \mathrm{mg} \text { twice daily } \\
\text { for } 1 \text { week, then } 5 \mathrm{mg} \text { and } \\
10 \mathrm{mg} \text { in separate doses for } 1 \\
\text { week, then } 10 \mathrm{mg} \text { twice daily } \\
\text { Reduce dose in people with } \\
\text { renal impairment }\end{array}$ & $\begin{array}{l}\text { Target dose of } 5 \mathrm{mg} \mathrm{BD} \text { is recommended in patients } \\
\text { with severe renal impairment (creatinine clearance of } \\
5-29 \mathrm{~mL} / \mathrm{min} \text { based on the Cockroft-Gault equation) }\end{array}$ \\
\hline \multicolumn{3}{|l|}{ ANTIOXIDANTS } \\
\hline Vitamin $\mathrm{E}$ & not greater than 400 I.U. per day & \\
\hline Estrogen & & $\begin{array}{l}\text { early studies suggested that estrogen or hormone } \\
\text { replacement therapy may delay the onset of } \\
\text { Alzheimer's } \\
\text { Disease }\end{array}$ \\
\hline Gingko biloba & & \\
\hline
\end{tabular}


Table 7-Non-pharmacological approaches for the management of associated disorders of Alzheimer's disease (mild, moderate and severe)

\begin{tabular}{|c|c|}
\hline $\begin{array}{l}\text { Nonplanmacological approaches } \\
\text { for Common Belavioral Synip toms } \\
\text { and Mood Disorlers }\end{array}$ & NonPPhrmacobgical Interventions \\
\hline Apathy & $\begin{array}{l}\text { Stimulationlactivities } \\
\text { Simpletasks like visulal, audio, and games }\end{array}$ \\
\hline Sleep disturtances & $\begin{array}{l}\text { Sleep hygiene practices(praye, bath meditation) } \\
\text { Stimulation during the day } \\
\text { Roduction of excessive stimulation/ noise(Ex. Noise, TV) } \\
\text { Light disturbances } \\
\text { Color management of the room }\end{array}$ \\
\hline Wandeing & 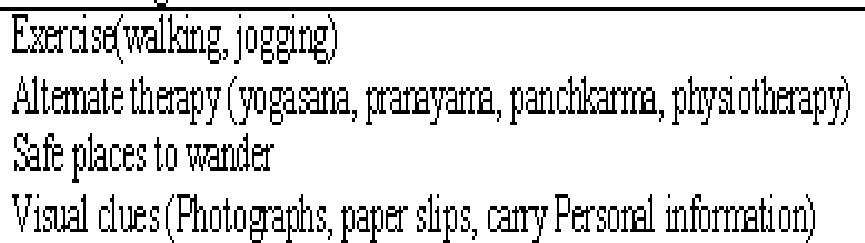 \\
\hline $\begin{array}{l}\text { Mood disorders } \\
\text { Psychotic symptoms }\end{array}$ & 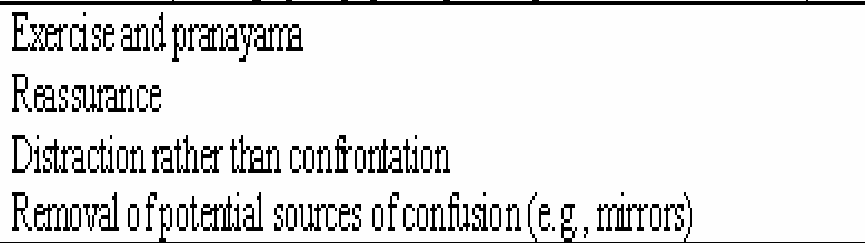 \\
\hline $\begin{array}{l}\text { Eatingappetite disorders } \\
\text { Irnitability/agitation }\end{array}$ & $\begin{array}{l}\text { Offering simple, finger foods } \\
\text { Removal of distactions from dining area } \\
\text { Soothing music(music therapy) } \\
\text { Breakdown of tasksinto simple steps } \\
\text { Redirection }\end{array}$ \\
\hline
\end{tabular}

